\title{
A prospective observational study of fetomaternal outcome in second stage caesarean section
}

\author{
Isha $^{1}$, Prabha Lal ${ }^{2}$, Vikram Dutta ${ }^{3}$, Aayushi Kaushal ${ }^{1 *}$
}

\author{
${ }^{1}$ Department of Obstetrics and Gynecology, PGIMER, Chandigarh, India \\ ${ }^{2}$ Department of Obstetrics and Gynecology, Lady Hardinge Medical College, New Delhi, India \\ ${ }^{3}$ Department of Paediatrics, Lady Hardinge Medical College, New Delhi, India
}

Received: 24 September 2019

Accepted: 16 November 2019

\author{
*Correspondence: \\ Dr. Aayushi Kaushal, \\ E-mail: kaushalaayushi@gmail.com
}

Copyright: () the author(s), publisher and licensee Medip Academy. This is an open-access article distributed under the terms of the Creative Commons Attribution Non-Commercial License, which permits unrestricted non-commercial use, distribution, and reproduction in any medium, provided the original work is properly cited.

\begin{abstract}
Background: Incidence of caesarean section is rapidly rising over last two decades and one fourth is contributed by caesarean section in second stage. The objective of this study was to study of fetomaternal outcome in second stage caesarean section.

Methods: Prospective observational study was done in 80 women undergoing second stage caesarean section from December 2015 to march 2017 at Lady Hardinge Medical Collage Delhi. These women observed from labour to caesarean section in second stage of labour till post-operative period for any complication. Intraoperative and postoperative complications were observed in these women.

Results: Caesarean section rate was $22 \%$ in which $3.9 \%$ were done in second stage of labour. Most common gestational age being 39-40 weeks (47\%). Most common indication being deep transverse arrest (41.25\%). Intraoperative complication as bladder injury (5\%), extension of uterine incision (23\%), PPH (33\%) and need for blood transfusion (31\%) and post-operative complication as wound sepsis in $58 \%$ and $20 \%$ requiring resuturing, postoperative fever, prolong hospital stay, prolonged catheterization etc. neonatal complications as severe birth asphyxia $(2.5 \%)$, respiratory distress $(55 \%)$, need for mechanical ventilation.

Conclusions: Thus, caesarean section done in second stage of labour is associated with increased maternal and neonatal morbidity.
\end{abstract}

Keywords: Caesarean section, Complication, Maternal and neonatal morbidity, Second stage of labour

\section{INTRODUCTION}

Caesarean section is the most commonly performed major abdominal operation and its incidence ranges from $0.4-42.3 \% .^{1,2}$ Incidence of caesarean section is rapidly rising over the last two decades. ${ }^{3}$

The reason is mainly attributed to the improved safety of anaesthetic intervention, surgical technique, advanced technology, knowledge of intensive care medicine, availability of blood and fear of litigation amongst obstetrician due to remote complication of birth asphyxia. Caesarean section performed in second stage of labour constitutes one fourth of all caesareans done and is associated with increased complication such as obstetric haemorrhage, injury to surrounding organs, extension of uterine incision leading to broad ligament haematoma formation, need for stepwise devascularisation, caesarean hysterectomy, ICU admission, increased infection and prolonged hospitalisation. ${ }^{4}$ Neonatal morbidity includes birth asphyxia, respiratory distress, NICU admission, fetal injury, neonatal septicaemia and neonatal seizure. 
Objective of this study was to determine the maternal and neonatal outcome in women undergoing second stage caesarean section.

\section{METHODS}

A prospective observational study was conducted in the department of obstetrics and gynaecology in collaboration with department of paediatrics, Lady Hardinge Medical College and Kalawati Saran Children's Hospital New Delhi from December 2015 to March 2017. 80 women were selected after fulfilling inclusion and exclusion criteria.

\section{Inclusion criteria}

- All uncomplicated singleton, term gestation > 37 weeks, with cephalic presentation, in second stage of labour were included.

\section{Exclusion criteria}

- Women with IUD, multiple pregnancy, not giving consent and women with obstetric complications like APH, FGR, GDM, previous caesarean.

Detailed history and examination were carried out and progress of labour was managed by partogram. Decision making for emergency second stage caesarean section, level of surgeon making decision and its indications, time from decision to delivery of baby interval and total duration of second stage of labour was recorded. Intra operative finding was recorded and complication such as extension of uterine incision, formation of broad ligament haematoma, bladder and bowel injury, PPH, blood transfusion, requirement of step wise devascularisation, caesarean hysterectomy and need for ICU admission if any was recorded. Neonates were evaluated in terms of birth weight, Apgar score at $1 \mathrm{~min}$ and $5 \mathrm{~min}$ of birth, requirement for resuscitation, birth asphyxia, NICU admission, need for mechanical ventilation, presence of hypoxic ischemic encephalopathy and fetal injury recorded by paediatrician of at least senior resident calibre. All neonates were observed till 7 days of birth for complications if any.

\section{Statistical analysis}

The data was be collected and recorded on SPSS (Statistical package for social sciences) version 18. All the qualitative variables were recorded and percentages and proportions were calculated. The association between qualitative dependent variables and the outcome variables were analyzed by using Chi square test. For calculating the strength of association Odds ratio was calculated. In quantitative variables - mean and standard deviation was calculated and for testing the statistical relation of the quantitative dependent variable with the outcome variable student " $t$ " test was applied. The association between quantitative dependent variables and the outcome variables will be analyzed by using Chi square test. The $p$ value of less than 0.05 will be taken as statistically significant for commenting upon association.

\section{RESULTS}

Total number of deliveries during this period was 22014 , out of which NVD were 17165 and caesarean deliveries were 4849 . Thus, caesarean section rate was $22 \%$ out of which $3.9 \%$ caesarean sections were done in second stage of labour. Second stage CS compared to $1^{\text {st }}$ stage is associated with increased complications.

Table 1: Distribution as per gestational age.

\begin{tabular}{|llc|}
\hline $\begin{array}{c}\text { Gestational } \\
\text { age (weeks) }\end{array}$ & Number of women (n) & \begin{tabular}{c} 
Percentage \% \\
\hline$<38$
\end{tabular} \\
\hline $38-39$ & 20 & 13.75 \\
\hline $39-40$ & 35 & 25 \\
\hline $40-41$ & 12 & 43.75 \\
\hline$>41$ & 2 & 15 \\
\hline Total & 80 & 2.5 \\
\hline
\end{tabular}

On analyzing the Table 1 it was found that out of 80 women, 11 women $(13.75 \%)$ were of gestational age $<38$ weeks, 20 women (25\%) had gestational age of 38-39 weeks, 35 women $(43.75 \%)$ belonged to gestational age of $39-40$ weeks, 12 women $(15 \%)$ had gestational age between 40-41 weeks, and only 2 women (2.5\%) had gestational age of $>41$ weeks.

Table 2: Distribution of women according to labour characteristics.

\begin{tabular}{|llll|}
\hline Labour characteristics & & Number of women $(\mathbf{n})$ & Percentage $\%$ \\
\hline \multirow{2}{*}{ Onset of labour } & Spontaneous & 69 & 86.25 \\
\cline { 2 - 4 } & Induced & 11 & 13.75 \\
\hline Oxytocin augmentation & Done & 50 & 62.5 \\
\hline PROM & Present & 22 & 27.5 \\
\hline Frequency of $\mathrm{P} / \mathrm{V}>4$ & Present & 41 & 51.25 \\
\hline
\end{tabular}

Table 2 shows the labour characteristics of women who had undergone second stage caesarean section. Majority
69 out of $80(86.25 \%)$ women had spontaneous onset of labour and 11 out of 80 women $(13.75 \%)$ required 
induction of labour. 50 out of 80 women $(62.5 \%)$ required oxytocin augmentation. 22 women $(27.5 \%)$ had PROM. Multiple $\mathrm{P} / \mathrm{V}$ examination $\geq 4$ in number was observed in 41 women $(51.25 \%)$ leading to increased incidence of post-operative wound sepsis.

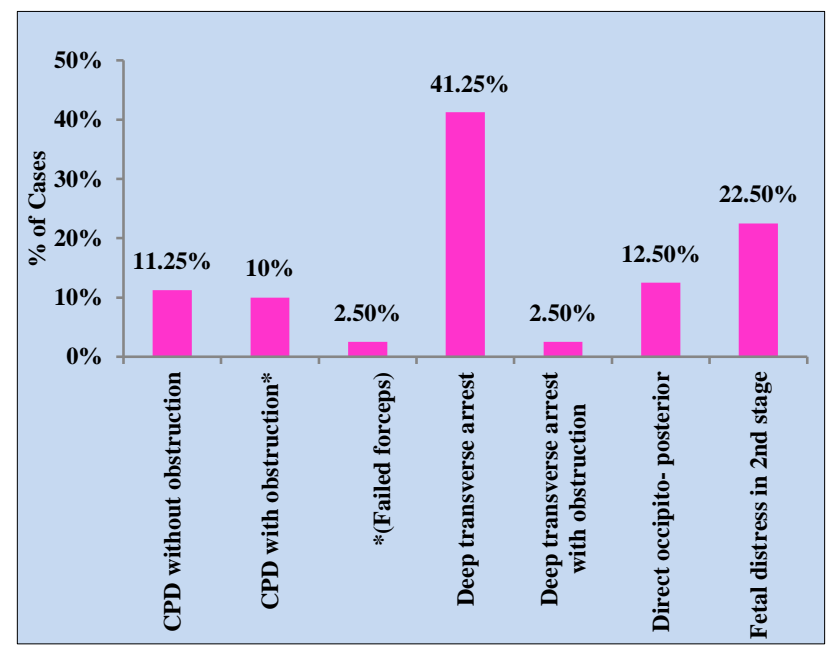

Figure 1: Distribution of the women according to indication for caesarean section.

Table 3: Distribution of women according to intraoperative complications.

\begin{tabular}{|lll|}
\hline $\begin{array}{l}\text { Intra operative } \\
\text { complication }\end{array}$ & $\begin{array}{l}\text { Number of } \\
\text { women (n) }\end{array}$ & $\begin{array}{l}\text { Percentage } \\
\%\end{array}$ \\
\hline Bladder injury & 4 & $5 \%$ \\
\hline Extension of incision & 19 & $23.75 \%$ \\
\hline $\begin{array}{l}\text { Broad ligament } \\
\text { haematoma }\end{array}$ & 2 & $2.5 \%$ \\
\hline PPH Total & 27 & $33.75 \%$ \\
\hline $\begin{array}{l}\text { Atonic } \\
\begin{array}{l}\text { Traumatic } \\
\text { transfusion }\end{array}\end{array}$ & 10 & $12.5 \%$ \\
\hline
\end{tabular}

This Figure 1 depicts that CPD was seen in 17 out of 80 women $(22.25 \%)$ in which 9 women $(11.25 \%)$ had CPD without obstruction, 8 women $(10 \%)$ had CPD with obstruction. $43.75 \%$ had DTA and $2.5 \%$ had DTA with obstruction. Direct occipito posterior was present in $12.5 \%$ and fetal distress in $22.5 \%$. Caesarean section done with obstructive features had increased risk of intraoperative and post-operative complication.

Thus, most common indication for second stage caesarean section was deep transverse arrest (41.25\%) and least common indication failed forceps $(2.5 \%)$.

Table 3 shows intra operative complications in women with second stage caesarean section. Bladder injury was present in 4 out of 80 women $(5 \%)$, extension of uterine incision in 19 out of 80 women $(23.75 \%)$ and broad ligament hematoma in 2 out of 80 women (2.5). 27 women out of $80(33.75 \%)$ had PPH in which $12.5 \%$ had atonic and $21.25 \%$ women had traumatic PPH. 25 out of 80 women $(31.25 \%)$ required blood transfusion.

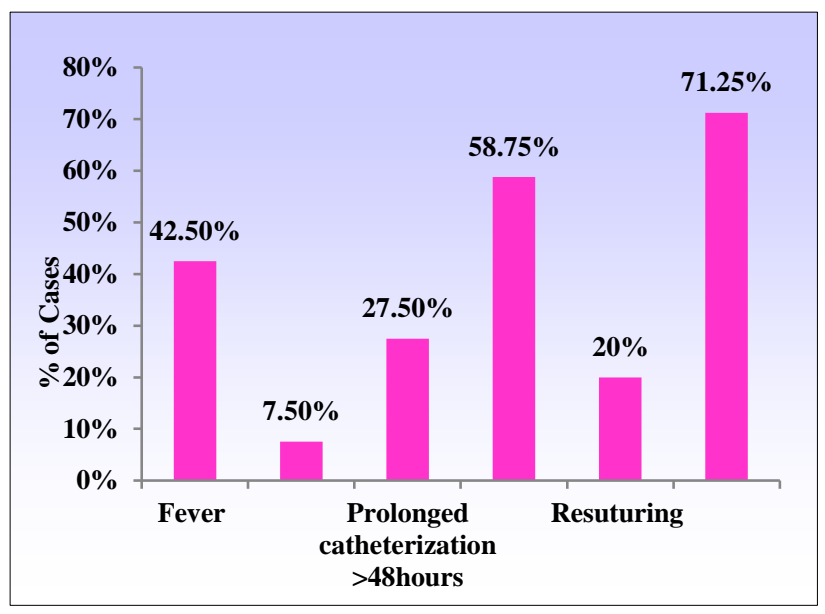

Figure 2: Distribution of women according to postoperative complication.

Figure 2 depicts the presence of various complications in post-operative period. Out of 80,34 women $(42.5 \%)$ had fever, 6 out of 80 women $(7.5 \%)$ had paralytic ileus and 22 out of 80 women $(27.5 \%)$ had prolonged catherization (> 48 hours). Wound sepsis was present in 47 out of 80 women $(58.75 \%)$ and 16 out of 80 women $(20 \%)$ required resuturing of abdominal wound. $71.25 \%$ of women had hospital stay of $>7$ days.

Table 4: Distribution of woman according to pre-operative and post-operative $\mathrm{Hb}$.

\begin{tabular}{|lllll|}
\hline $\begin{array}{l}\text { Haemoglobin in } \\
\text { gm/dl }\end{array}$ & $\begin{array}{l}\text { Number of women } \\
\text { with pre-0perative } \\
\text { Hb level (n) }\end{array}$ & $\begin{array}{l}\text { Percentage } \\
\%\end{array}$ & $\begin{array}{l}\text { Number of women with } \\
\text { post-operative Hblevel } \\
\text { (n) }\end{array}$ & $\begin{array}{l}\text { Percentage } \\
\%\end{array}$ \\
\hline $12-14$ & 26 & 32.5 & 0 & 0 \\
\hline $10-11.9$ & 42 & 52.5 & 22 & $27.5 \%$ \\
\hline $8.9-9.9$ & 12 & 15 & 39 & $48.75 \%$ \\
\hline$<8.9$ & 0 & 0 & 19 & $23.75 \%$ \\
\hline Mean \pm SD & $11.35 \pm 1.11$ & & $9.32 \pm 0.86$ & \\
\hline Mean difference \pm SD & $2.04 \pm 0.85$ & & & \\
\hline
\end{tabular}


This Table 4 depicts the haemoglobin level in women in pre and postoperative period. Mean $\mathrm{Hb}$ level preoperatively was $11.35 \pm 1.11 \mathrm{gm} \%$ while mean postoperative $\mathrm{Hb}$ level was $9.32 \pm 0.86$ gm\%. Preoperative $\mathrm{Hb}$ level was between $10-11.9 \mathrm{~g} / \mathrm{dl}$ of 42 women $(52.5 \%)$, $12-14 \mathrm{~g} / \mathrm{dl}$ of 26 woman $(32.5 \%), 8.9-9.9 \mathrm{~g} / \mathrm{dl}$ of 12 woman $(15 \%)$ and none of them had $\mathrm{Hb}$ level of $<8.9$ g/dl. Postoperative $\mathrm{Hb}$ level of same women was between $8.9-9.9 \mathrm{~g} / \mathrm{dl}$ of 39 women $(48.75 \%), 10-11.9 \mathrm{~g} / \mathrm{dl}$ in 22 women $(27.5 \%)$, $<8.9$ in 19 women $(23.75 \%)$ and none had $\mathrm{Hb}$ between $12-14 \mathrm{~g} / \mathrm{dl}$. The mean difference in both was $2.04 \pm 0.85$. Thus, there was a significant fall in haemoglobin level $(11.35 \pm 1.11$ versus $9.32 \pm 0.86$ with $p$ value of $<0.001)$.

Table 5: Distribution according to neonatal complication.

\begin{tabular}{|lll|}
\hline Fetal complication & Number on neonates (n) & Percentage $\%$ \\
\hline Severe birth asphyxia & 2 & $2.5 \%$ \\
\hline Respiratory distress & 44 & $55 \%$ \\
\hline Requirement for resuscitation & 46 & $57.5 \%$ \\
\hline Birth injury (failed forceps) & 2 & $2.5 \%$ \\
\hline Need for mechanical ventilation/resuscitation with IPPV & 12 & $15 \%$ \\
\hline
\end{tabular}

Table 5 shows the distribution of women according to presence of fetal complication and it was found that $57.5 \%$ of neonates required resuscitation after delivery in the form of bag and mask ventilation. Birth in injury was seen in $2.5 \%$ and $15 \%$ required mechanical ventilation with IPPV.

\section{DISCUSSION}

The present study was prospective observational study conducted in the department of obstetrics and gynaecology at Lady Hardinge Medical College and Smt. Sucheta Kriplani Hospital, New Delhi from December 2015 to March 2017. Caesarean section rate was $22 \%$ out of which $3.9 \%$ were done in second stage of labour. In the present study the mean gestational age of women was $38.6 \pm 2.15$ weeks which was comparable to the study done by Asicioglu et al $(38.9 \pm 0.9$ weeks $)$, Das $S$ et al $(38.5 \pm 1.29$ weeks $) .^{5,6}$

A total $86.25 \%$ women had spontaneous onset of labour and $13.75 \%$ required induction of labour and $63.75 \%$ required oxytocin augmentation. In the similar study by Jain et al, it was observed that $80 \%$ women had spontaneous onset of labour and $86 \%$ required oxytocin augmentation. ${ }^{7}$ Thus, it is obvious from above study that though onset of labour may be spontaneous yet they require oxytocin augmentation usually due to slow progress of labour due to uterine inertia.

In the present study the most common indication for second stage caesarean section was DTA (43.75\%), followed by CPD (21.25\%) which was comparable to the study by Jain et al, Jayaram $\mathbf{J}$ et al. ${ }^{7,8}$ Mean duration of first and second stage of labour was 12.69 \pm 1.78 hours and $2.39 \pm 0.6$ hours respectively which was comparable to the study carried out by Allen et al. ${ }^{4}$ Mean duration from decision to delivery interval was 2.2 hour which was comparable to results obtained by Jain et al. ${ }^{7}$ Women with longer decision to delivery interval were associated with increased per operative complication due to increased attenuation of LUS and impaction of fetal head predisposing them to have more extension of uterine incision, PPH and bladder injury.

\section{Maternal outcome}

In the present study bladder advancement and thinning of LUS was present in $68.75 \%$ and $65 \%$ respectively which was comparable to the study conducted by Shobha $\mathrm{T}$ et al. ${ }^{9}$ Average duration of surgery in the present study was observed 96 minutes, ranging from $60 \mathrm{~min}$ - 150 minutes and was comparable to the study done by Jain et al, Asicioglu et al and Prameela et al and Moodley et al observed the average duration of surgery $35 \mathrm{~min}$, with range of $51.21 \pm 2.6 \mathrm{~min}$ and 69 minutes respectively. $5,7,10,11$

\section{Intraoperative complication}

In the present study bladder injury was found in $5 \%$ women which was almost comparable to the study done by Das $\mathrm{S}$ et al and Asicioglu et al and extension of uterine incision was observed in $6.4 \%$ women which was similar to the study conducted by Allen et al. ${ }^{4-6}$ The reason for increased bladder injury and extension of uterine incision in second stage caesarean can be due to presence of bladder advancement and thinned out edematous lower uterine segment.

Postpartum haemorrhage (PPH) was observed in $33.75 \%$ women and $0.9 \%$ women required blood transfusion which was comparable to study conducted by Asicioglu et al, Narayen $\mathbf{J}$ et al and Shobha $\mathbf{T}$ et al. ${ }^{5,8,9}$ The reason for increased occurrence of PPH may be due to increased risk of uterine wound extension causing traumatic $\mathrm{PPH}$ as a result of technical difficulty and presence of atonic PPH due to prolonged labour leading to uterine inertia. Broad ligament haematoma was present in $2.5 \%$ women comparable to Malathi $\mathrm{J}$ et al. ${ }^{12}$ 


\section{Post-operative complication}

In the present study prolonged catheterization of $>48$ hours were present in $27.5 \%$ women of which $5 \%$ had bladder injury was comparable to the study conducted by Jain et al. ${ }^{7}$ Febrile morbidity was present in $42.5 \%$ women postoperatively which was comparable to the study done by Jain at al $38 \% .^{7}$ On contrary study done by Malathi $\mathrm{J}$ et al found febrile morbidity in $16 \%$ while Allen et al had seen it only in $1.1 \%$ cases. $^{4,12}$

A total $7.5 \%$ of women developed paralytic ileus in the post-operative period which was $2 \%$ in study by Malathi $\mathrm{J}$ et al and $29 \%$ in study by Jain et al. ${ }^{7,12}$ Wound infection rate in the present study was $66.25 \%$ and $20 \%$ of them required re suturing of wound which was higher than the study by Malathi $\mathrm{J}$ et al where wound infection rate of $12 \%$ and $8 \%$ required re suturing. ${ }^{12}$ Higher percentage of wound infection was due to prolonged leak $\mathrm{P} / \mathrm{V}$, multiple $\mathrm{P} / \mathrm{V}$ examination of $(\geq 4)$.

\section{Neonatal outcome}

In the present study $2.5 \%$ neonates had low Apgar $<5$ and suffered from severe birth asphyxia. While Allen et al, observed severe birth asphyxia in $11 \%$ neonates. ${ }^{4}$ In the study by Jain et al $36.3 \%$ neonates required resuscitation whereas in present study resuscitation was required in $57.5 \%$ of neonates. ${ }^{7}$ NICU admission was required in $13.7 \%$ neonates which was comparable to study by Das $\mathrm{S}$ et al where $12 \%$ of neonates required NICU admission. ${ }^{6}$ In the present study $2.5 \%$ neonates sustained birth injury due to failed instrumental delivery. Neonatal death was seen in $2.5 \%$ in present study, comparable to the study by Jain et al where neonatal death had occurred in $3.7 \%$ of neonates. ${ }^{7}$

\section{CONCLUSION}

Women with prolonged duration of second stage were associated with increased maternal and neonatal complication. Intraoperative complications were seen like extension of uterine extension, bladder injury, $\mathrm{PPH}$, blood transfusion and broad ligament hematoma. Postoperative complication in these women was fever, wound sepsis, paralytic ileus, prolonged catheterization and prolonged hospital stay.

Neonatal complications were severe birth asphyxia, low Apgar, birth injury, NICU admissions and early neonatal death. Thus, caesarean section in second stage is associated with increased maternal and fetal morbidity and requires special care. Emphasis should be focused on assuring normal progression of labour and proper use of partogram.
Funding: No funding sources

Conflict of interest: None declared

Ethical approval: The study was approved by the Institutional Ethics Committee

\section{REFERENCES}

1. Dumont L, De Bernis MH, Bouvier C, Breat G, MOMA study group. Caesarean section rate for maternal indication in sub-Saharan Africa: a systematic review. Lancet. 2001;358:1328-33.

2. Zizza A, Tinelli I, Malvasi A, Barbone E, Stark M, Guido M, et al. Caesarean sections in the World: a new ecological approach. J Prevent Med Hyg. 2011;52:4.

3. Martin A, Hamilton BE, Ventura SJ, Osterman MJ, Kirmeyer S, Maathews TJ, et al. Birth: final data for 2009. Natl Vital Stat Rep. 2011;60:1-70.

4. Allen VM, O'Connell CM, Basket TF. Maternal morbidity associated with caesarean delivery without labour compared with spontaneous onset of labour at term. Int J Gynaecol Obstet. 2003;102:477-82.

5. Asicioglu O, Gungorduk K, Yildrim G, Cemal Ark. Second stage versus first stage caesarean delivery comparison of maternal and perinatal outcomes. J Obstet Gynecol. 2014;1:7.

6. Das S, Sarkar SK. Fetomaternal outcome in second versus first stage caesarean delivery in a tertiary rural medical collage. IOSR J Dent Med Sci. 2014;13(12):28-30

7. Jain N, Prabha Lal. A retrospective comparative study of feto-maternal outcome in first and second stage caesarean section. Int $\mathrm{J}$ Reprod Contracep Obstet Gynecol. 2016;5(7):2282-6.

8. Jayaram J, Mahendra G, Vijayalakshmi S. Fetomaternal outcome in Caesarean sections done in second stage of labour. Indian J Obstet Gynecol India. 2016:3:51-4.

9. Shobha $\mathrm{T}$, Jothi. The study of maternal and neonatal outcome of primary cesarean section at term - influence of labour and stage. International journal of science and research. 2016;5(4):2213-8.

10. Prameela. Comparison of obstetric and neonatal outcome between first and second stage caesarean sections in tertiary hospital MMC and RI, Mysore. Int J Recent Trends Sci Technol. 2015;14(3):520-2.

11. Moodley J, Devjee j, Khedun SM, Esterhuizen T. Second-stage primary Caesarean deliveries: Are maternal complications increased. SA Fam Pract. 2009;51(4):328-31.

12. Malathi J, Venigalla S. Comparison of obstetric outcome between first and second stage caesarean sections in rural tertiary hospital. Int J Pharma Biomd Res. 2012;3(4):222-5.

Cite this article as: Isha, Lal P, Dutta V, Kaushal A. A prospective observational study of fetomaternal outcome in second stage caesarean section. Int $\mathbf{J}$ Reprod Contracept Obstet Gynecol 2019;8:4798-802. 